\title{
Exploration and Practice on Course Teaching in Plastic Injection Mold
}

\author{
https://doi.org/10.3991/ijet.v13i06.8497 \\ Xin Li \\ Agricultural University of Hebei, Baoding, China \\ lixin20131113@163.com
}

\begin{abstract}
The plastic injection mold design course has strong comprehensiveness and practicality. However, most theoretical teaching are separated from practical operation in the current teaching process. The blind lecture of teachers easily leads to the cramming education phenomenon, which has low student acceptance and poor learning effect. To solve these problems, the project-driving method was applied to plastic injection mold design teaching. On the basis of the course content, the present study expounded the implementation method of project-driven teaching which divided the course teaching process into the following stages: determining the theme, executing the theme, and displaying and evaluating the project. The following were also detailed: the principles of project selection, the implementation process of the project, and the tasks of students and teachers in the implementation process, as well as the project result presentation and the evaluation criteria of the quality of student learning. The plastic injection mold design of the refrigerator thermostat knob was used as an example to discuss the application of the project-driving method. Results show that compared with traditional teaching methods, the project-driving teaching method can better improve the learning interest, self-learning ability, engineering practice ability, and innovation and teamwork of students, as well as the satisfaction of employers.
\end{abstract}

Keywords-Plastic injection mold design, project-driving method, course teaching, practical ability

\section{Introduction}

Plastic injection mold design is one of the professional technical courses in Mold design and manufacturing profession and is the key course in mechanical manufacture and automation profession. With its strong comprehensiveness and practicality, plastic injection mold design has become a core subject for cultivating vocational skills of design, production, and management in the mold industry. Existing survey results have shown the separation of current theoretical teaching methods of this course from practical applications in most colleges and universities. As a result, students cannot really understand the teaching content, leading to failure in mold design practice. 
Considering this undesirable teaching effect, we can summarize the main problems in the teaching process as follows:

1. The theory course easily results in cramming education which fails to fully mobilize the learning initiative and enthusiasm of students. With poor teaching effectiveness, students will regard mold design principles and trivial content as difficult and boring. In addition, although many knowledge points exist in plastic injection mold design teaching, seeking the relationship between these knowledge points is difficult for students. Previously learned content will be forgotten with time. Thus, only some fragmented knowledge points are ultimately accepted without systematization.

2. Teaching assessment is executed through examinations and usual performance indicated by attendance, homework, and recitation. Examinations are mainly prepared on the basis of textbook content, thereby increasing student dependence on textbooks. Evaluating the operational capacity, innovation capacity, and learned knowledge application of students in practice is difficult. Moreover, the ability to adapt to mold jobs is not improved, which negative impacts the future employment of students.

To meet the social requirements for talent in the mold industry, an important direction for curriculum reform is to improve the self-learning ability and overall quality of students when knowledge is taught [1-2]. The project-driving approach refers to the teaching method in which knowledge content in the traditional disciplinary system is transformed into a number of teaching projects. Courses are taught around projects, directly involving students to complete the teaching process. The main feature of the project-driving method is the fact that course teaching is always conducted around projects. The focus of this method is to cultivate the practice, innovation, independent access to information and the independent knowledge-building abilities of students. In the current study, the project-driving method was used in the course teaching of plastic injection mold design, and specific implementation methods were introduced with the case.

\section{$2 \quad$ State of art}

Educators have performed much research to develop the practice and knowledge application abilities of students. Zhang Wenyu (2014) explored the aspects of the curriculum system, teaching methods, and teaching staff construction, to build a strong and high-level teaching body by improving teaching quality [3]. Li Baoming (2014) conducted reforms in the practicability and integration of course content, the diversification of teaching resources, the informatization of teaching methods and tools, and the projectization of teaching management [4]. These reform measures are teacher-centered and curriculum-oriented, making them conducive to exploiting the role of teachers. However, the theoretical value of the mode is more than its practical value, separating theories from practice, which is not conducive to the cultivation of 
professional abilities of students. The teaching method also lacks unique characteristics due to its neglect of practical demands.

Wang Cuifeng (2014) proposed the curriculum model of school-enterprise cooperation [5]. Bi Dasen (2012) advocated the establishment of the industry-universityresearch base and the cultivation of student ability to serve enterprises [6]. Linda P. (2011) applied the dual system from German in the teaching process, allowing the cultivation of skilled talents to be shared by enterprises and schools [7]. The potential of applying this mode to Asia was demonstrated by Stefan [8]. In comparison, foreign companies have strong interest in school teaching participation due to their increased social responsibility and corporate development. However, many Chinese enterprises are not interested in school teaching for various reasons. Enterprises commonly refuse schools.

Based on work process, the project-driving teaching method brings an actual enterprise project into the curriculum. Driven by this mission, students can quickly grasp the basic theory of a curriculum, organically integrating theory with practice. Scholars have conducted studies on the project-driving teaching method. According to Zhang Shijin (2014), the project method is student-centered, providing room for the potential of students for innovation and practical ability [9]. The stages and the implementation process of the project-driving method were described by Gulimzhan [10]. Emine(2014) also demonstrated the effectiveness of this method in enhancing the social skills of students through examples. In the current study, project-driving method was used in the plastic injection mold design course teaching [11]. Actual projects and cases of enterprises were integrated into the teaching process with a specific implementation process.

\section{Teaching mode of plastic mold design based on the project- driving method}

The project-driving method refers to the teaching practices of teachers and students to complete specific tasks. Teaching focus is transited from lesson plan to project completion. In the project-driving method, a typical project is selected as the general task throughout the teaching process. The total task is divided into a number of specific subtasks according to knowledge points, integrating main contents of the course into various stages of the total task. Thus, scattered knowledge in various chapters of textbooks is organically linked to help students construct a complete knowledge system. In accordance with project-driving teaching theory and the teaching content of plastic injection mold design, the teaching process is divided into the following three stages:

\subsection{Identification of project themes}

The themes of learning units are determined according to the teaching program and curriculum objectives. The course project design should be close to the enterprise. The project should be based on the typical workflow of mold design, and it should be 
practical and pertinent and close to the actual conditions of the school. A large, comprehensive project is first identified to achieve the goal of curriculum development. The large project is then gradually divided into a number of small projects with easy operation and implementation. The small projects usually involve main knowledge points of a unit and typical tasks are formulated to implement them. Before arranging project tasks, teachers explain relevant theoretical knowledge. This, the introduction of project topics focused on inspiring student thinking. The project tasks are then clearly arranged with detailed project objectives, implementation plans, training skills, inspection capabilities, assessment methods, and reference books.

\subsection{Implementation of project activities}

Project groups are established, and a project leader is appointed for each group. The responsibility of group leaders includes project plan preparation guided by teachers, task assignment, and implementation supervision. Project plan is then formulated. Each team member designs a plan based on theoretical knowledge from the textbook or from self-study bibliography. A scientific and reasonable implementation plan is finally established after each plan is evaluated through group discussion. Each group then divides the tasks on the basis of the implementation plan. The work of each member is carried out according to the undertaken project tasks. During project implementation, teachers need to inspect work progress as well as the organization and management of each group, ensuring the quality and order of project implementation. For problems from students, teachers should provide answers and technical guidance to arouse the enthusiasm and thinking ability of students. Students are also encouraged to solve problems through information search to improve their self-learning abilities and to link theory to practice. After project task completion, students need to check the results by themselves. Meanwhile, teachers tour the groups to examine the progress and quality of group tasks. The learning situation of students is observed and is used as the evaluation reference after project completion.

\subsection{Demonstration and evaluation of project activities}

After project completion, teachers check and accept the project achievements of students. Projects are evaluated and rated according to workload, accomplishment, and achievement quality. The criteria include "whether the project results meet the requirements" and "whether expected teaching objectives are achieved." Groups and individuals are evaluated. For groups, the completion and quality of the whole project are evaluated. By contrast, individual evaluation includes learning attitude, individual task completion, project implementation participation, and professional quality and ability. After consulting professional teachers about scoring statistics, the following judgment matrix was obtained: 


$$
A=\left|\begin{array}{cccc}
1 & a_{12} & L & a_{1 n} \\
\frac{1}{a_{12}} & 1 & L & a_{2 n} \\
M & M & M & M \\
\frac{1}{a_{1 n}} & 1 & a_{2 n} & L
\end{array}\right|
$$

After calculating and normalizing the eigenvector of judgment matrix (A), we can determine the evaluation indicators and weights $\left(\mathrm{w}_{\mathrm{i}}\right)$ of student learning quality (Table 1).

$$
W_{i}=\sqrt[n]{\prod_{j=1}^{n} a_{i j}} / \sum_{i=1}^{n} \sqrt[n]{\prod_{j=1}^{n} a_{i j}}
$$

In addition, teachers review the theoretical knowledge of the whole project to comment on student performance. After completing the project, teachers document student achievements on file, including their project drawings, manuals, and the implementation process.

\begin{tabular}{|c|c|c|c|}
\hline \multicolumn{2}{|c|}{ Project stage } & \multicolumn{2}{|c|}{ Evaluation index } \\
\hline Content & Weight & Content & Weight \\
\hline \multirow{3}{*}{ Preparation } & \multirow{3}{*}{0.2} & Material search & 0.06 \\
\hline & & Learning attitude & 0.07 \\
\hline & & Self-learning ability & 0.07 \\
\hline \multirow{6}{*}{ Implementation } & \multirow{6}{*}{0.5} & Assigned workload & 0.08 \\
\hline & & Organization and plan & 0.08 \\
\hline & & Practical ability & 0.1 \\
\hline & & Communication and cooperation & 0.08 \\
\hline & & Hard work & 0.08 \\
\hline & & Inspection and correction & 0.08 \\
\hline \multirow{6}{*}{ Achievement } & \multirow{6}{*}{0.3} & Group project performance & 0.06 \\
\hline & & Individual task performance & 0.04 \\
\hline & & Group project quality & 0.06 \\
\hline & & Individual task quality & 0.04 \\
\hline & & Project presentation & 0.06 \\
\hline & & Defense performance & 0.04 \\
\hline
\end{tabular}

Table 1. Index and weights of student learning quality evaluation 


\section{Case study and teaching effectiveness}

\subsection{Teaching case}

The total project of this course was determined as the Injection Mold Design of the Refrigerator Thermostat Knob. Table 2 shows project content division according to the curriculum training objectives and knowledge of each unit.

Table 2. Project contents and task division of the plastic injection mold design

\begin{tabular}{|c|c|c|}
\hline Total project & Project division & Work tasks \\
\hline \multirow{13}{*}{$\begin{array}{l}\text { Injection Mold } \\
\text { Design of Re- } \\
\text { frigerator Ther- } \\
\text { mostat Knob }\end{array}$} & \multirow{4}{*}{$\begin{array}{l}\text { Project 1: Product analysis of } \\
\text { plastic parts }\end{array}$} & Task 1: Select plastic raw materials \\
\hline & & Task 2: Design structural machinability \\
\hline & & Task 3: Select molding process \\
\hline & & Task 4: Establish overall mold design and layout \\
\hline & $\begin{array}{l}\text { Project 2: Determination of Injec- } \\
\text { tion molding process parameters }\end{array}$ & $\begin{array}{l}\text { Determine parameters of temperature, pressure, } \\
\text { and time }\end{array}$ \\
\hline & $\begin{array}{l}\text { Project 3: Selection of injection } \\
\text { molding equipment }\end{array}$ & $\begin{array}{l}\text { Determine injection machine according to injection } \\
\text { molding process parameters }\end{array}$ \\
\hline & \multirow{7}{*}{$\begin{array}{l}\text { Project 4: Design of injection mold } \\
\text { structure }\end{array}$} & Task 1: Determine basic structure of the mold \\
\hline & & Task 2: Design gating system \\
\hline & & Task 3: Design forming parts \\
\hline & & Task 4: Check forming parts \\
\hline & & Task 5: Design introducing mechanism \\
\hline & & Task 6: Design guide mechanism \\
\hline & & Task 7: Select standard mold base \\
\hline
\end{tabular}

Product analysis of plastic parts. Teachers provide product photos or samples to define design tasks. According to product usage and molding process, students analyze the plastic molding process to select plastic raw materials. Combined with theoretical knowledge from textbooks, the structural machinability of plastic parts is analyzed from aspects of size, surface shape, internal structure, wall thickness, inserts, whorls, and holes. On the basis of shape structure, mold joints of plastic parts are then determined. The location of mold joints is conducive to mold processing, exhaust, demoulding, surface quality of plastic parts, and process operation. The number of cavities is calculated on the basis of processing accuracy, production volume, and processing costs of plastic parts. We should then determine the pouring system, including gate location, number of gates, gate size, and flow path layout. The Moldflow software is used for analysis and optimization, requiring students to draw a simple layout of the pouring system (Figure 1). 


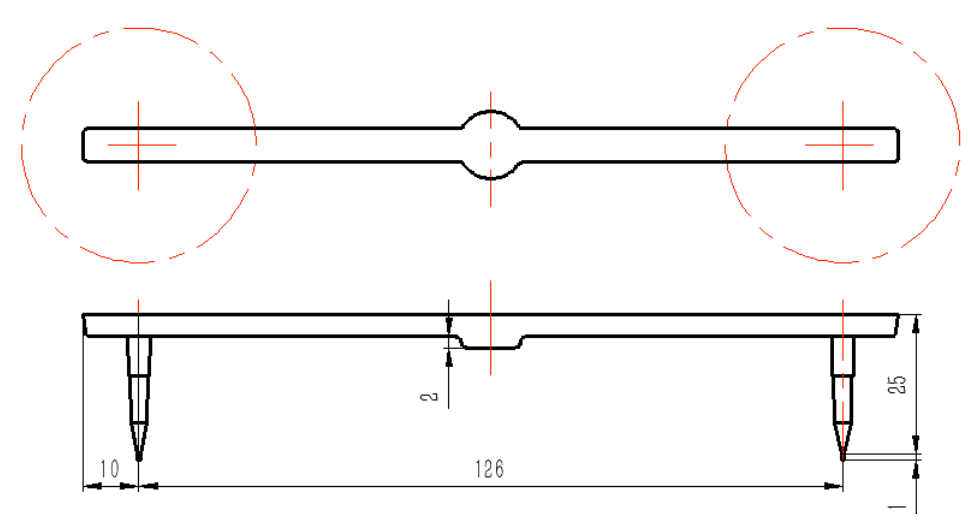

Fig. 1. Flow channel layout and size

Determination of injection molding process parameters. Reasonable process parameters ensure good plasticization of plastic melt and smooth filling, cooling, and setting to produce qualified plastic parts. Temperature, pressure, and time are the three most important parameters affecting the injection molding process. Barrel and mold temperatures are involved in the temperature index as the former mainly controls the plasticizing property and fluidity of the plastic, and the latter affects cooling setting and the capability of the plastic to fill the cavity. By overcoming the flow resistance of plastic melt, injection pressure can provide melt with a certain rate of mold filling to compress it. Labor productivity and injection machine use are directly affected by molding practice. Therefore, the length of relevant stages in the molding cycle should be minimized to guarantee quality. Teachers explain relevant knowledge on the process parameters of injection molding. Then, students consult the process conditions of plastic molding according to the plastic molding situation, formulating plastic molding process cards (Table 3 ).

Table 3. Polypropylene injection molding process parameters

\begin{tabular}{|l|l|l|}
\hline \multicolumn{2}{|c|}{ Plastic name } & \multicolumn{1}{c|}{ Polypropylene } \\
\hline Injection molding machine type & Screw-type injection molding machine \\
\hline \multirow{3}{*}{ Preheating and drying } & Temperature $t /{ }^{\circ} \mathrm{C}$ & $80-100$ \\
\cline { 2 - 3 } & Time $\tau / \mathrm{h}$ & $1-2$ \\
\hline \multirow{3}{*}{ Barrel temperature $\mathrm{t} /{ }^{\circ} \mathrm{C}$} & Back end & $160-170$ \\
\cline { 2 - 3 } & Middle end & $165-180$ \\
\cline { 2 - 3 } & Front end & $170-190$ \\
\hline Mold temperature $\mathrm{t} /{ }^{\circ} \mathrm{C}$ & $80-90$ \\
\hline Injection pressure $\mathrm{p} / \mathrm{Mpa}$ & Injection time & $20-60$ \\
\hline \multirow{4}{*}{ Molding time $\tau / \mathrm{h}$} & High-voltage time & $0-3$ \\
\cline { 2 - 3 } & Cooling time & $20-90$ \\
\cline { 2 - 3 } & Total period & $50-160$ \\
\hline Screw speed $\mathrm{N} /\left(\mathrm{r} \cdot \mathrm{min}^{-1}\right)$ & & 48 \\
\hline
\end{tabular}


Select injection-molding equipment. Students need to estimate the size and weight of plastic parts. The injection molding machine should primarily be selected according to the following parameters: injection capacity, mode locking pressure, injection pressure, mold installation dimensions, ejection and distance, location hole size, and template stroke. Meanwhile, relevant parameters of the injection machine should be checked. Through the selection and checking of injection molding equipment, students can improve their understanding of the principle of injection molding to lay the foundation to further learn mold structure.

Design injection mold structure. Injection mold structure design is the key task of the project, which mainly includes the following aspects:

a) Design forming parts, including the structure design of the mode cavity and core and dimension calculation and strength check. The structure with side holes and concaves should be designed with a side core-pulling mechanism. Pumping distance and extraction force should also be calculated to determine the form, structure, and size of the core-pulling mechanism.

b) Design stripping mechanism after calculating stripping force. Sprue puller, ejector, and reset mechanisms should be determined. Then, the strength, stiffness, and stability of components should be checked.

c) Design clamping guide mechanism, including composed elements, structure size, and installation means.

d) Design temperature control system after calculating mold thermal balance, as well as design and calculation of the structure, size, and location of the cooling system.

e) Select specifications, models, and quantities of supporting and connecting parts.

After determining the mold structure plan, students are required to draw mold assembly illustrations. Figure 2 shows a mold assembly drawing that reflects structural characteristics, working principles, relative positions between parts, and assembly relationship of the mold.

After completing the project, students can display their project results via PPT, CAD drawings, hand-drawn illustrations, and homemade molds. Different groups are mutually evaluated after presentation. Students can re-learn learned knowledge, which enhances their interest in learning and sense of teamwork. Teacher evaluation is given on the basis of encouragement to enhance student confidence. In each link of the project process, teachers should establish complete dynamic evaluation files for students. The classroom discipline, attendance, data collection, and task completion of each student are recorded. Assessment information is included in the comprehensive evaluation results.

\subsection{Teaching effectiveness}

The project teaching method was introduced to the instruction of plastic mold courses in 2016, with teaching subjects comprising year 2013 undergraduates majoring in Mechanical Manufacturing and Automation. The traditional teaching method was performed on year 2012 undergraduates of the same major. After course completion, we conducted a questionnaire survey on students of both grades, with a followup survey on the enterprises where they work. Figure 3 shows the statistics from the survey. 


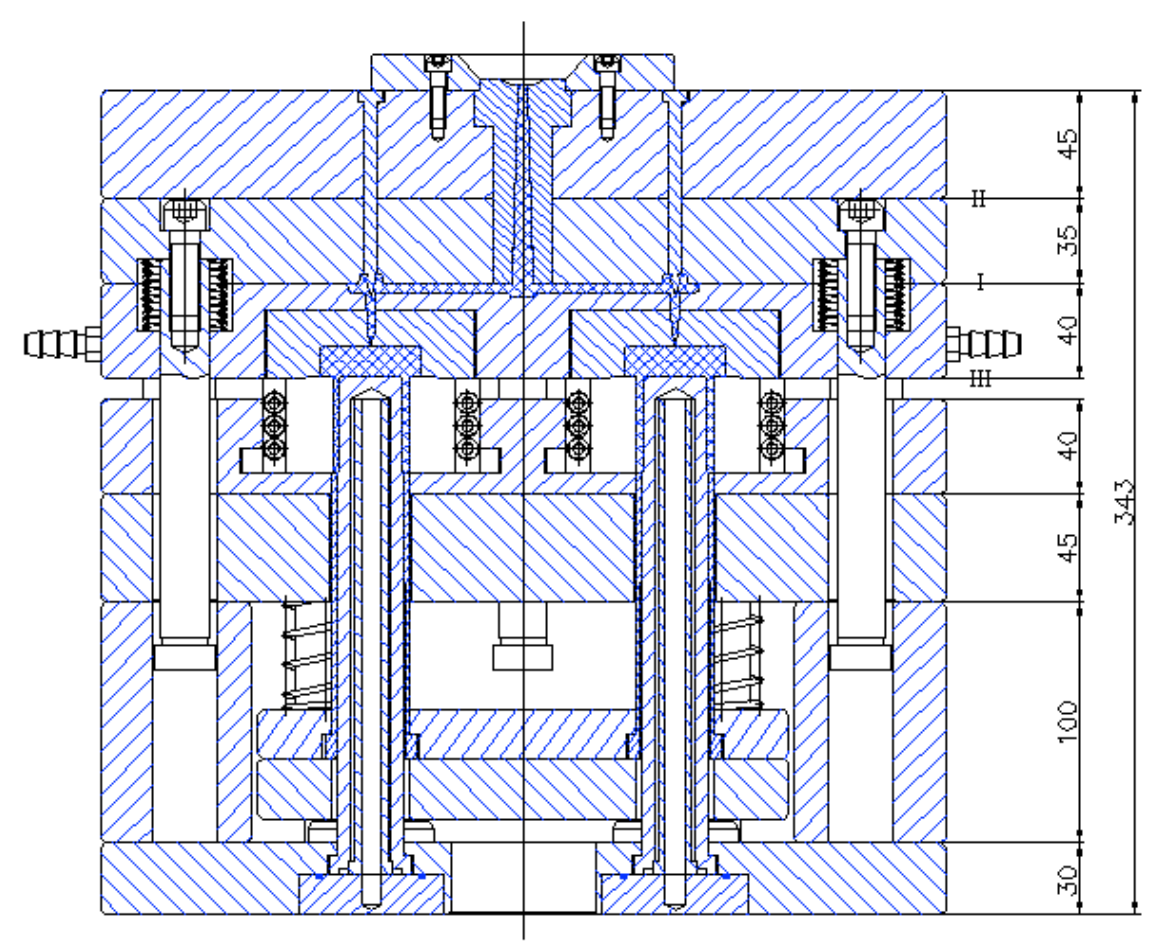

Fig. 2. Mold assembly drawing

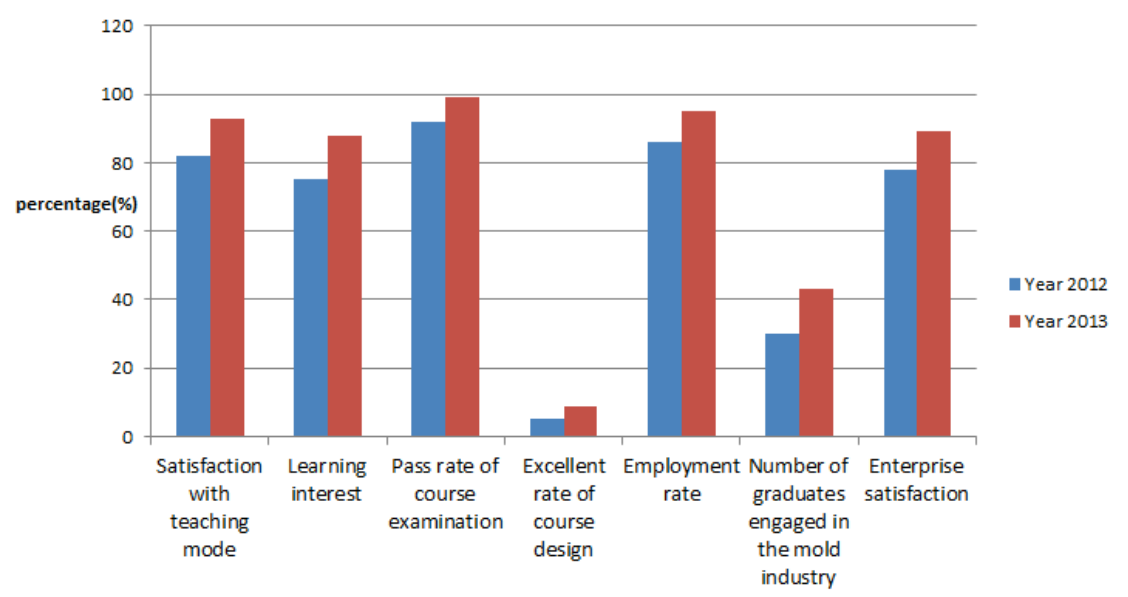

Fig. 3. Comparison chart of teaching effectiveness

The results show that the course reform significantly improves teaching acceptance. The employment rate, professional counterpart rate, and job adaptability of graduates were significantly enhanced after the reform. Meanwhile, the professional knowledge and skills of students were approved by their employers. 


\section{Conclusions}

By reforming the project-diving method, the core of the plastic injection mold design curriculum shifted from teacher to student, textbook to project, and classroom to practical experience. The following conclusions could be drawn:

1. The practice proves that students have a firm grasp of knowledge points with the use of this teaching method, allowing them to achieve teaching objectives and requirements.

2. Multiple abilities of students are improved, including knowledge acquisition, problem analysis, problem solving of practical production, teamwork, social relationship, and professional accomplishment.

3. This method could rapidly improve the teaching quality and effect of the plastic injection mold design course, cultivating high-quality talent in the plastic molding process and in the mold design for the country and society.

\section{Acknowledgments}

This study was supported by the teaching research project of Agricultural University of Hebei (Grant No. 2015YB23, No. 2018YB26).

\section{$7 \quad$ References}

[1] Tang Yan. Project-based Teaching reforms and practices for design of plastic molds, Essays of Sciences Education, 2014, vol. 294, pp. 90-91.

[2] Ji Jing, Sui Rendong and Li Shengduo and Hu Caiqi. Teaching reform and practice for the course of plastic molding process and mold design, China Modern Education Equipment, 2016, vol. 255, pp. 48-50.

[3] Zhang Wenyu, Liu Xianlan. Teaching reform and practice for the course of plastic molding process and plastic molds design, Education and Teaching Forum, 2014, vol.22, pp.220-221.

[4] Li Baoming. Research and exploration on the course of plastic molds design. Higher Education in Chemical Engineering, 2014, vol. 2, pp. 49-50.

[5] Wang Cuifeng, Xu Ning. Development and practice of die design and manufacturing major curriculum under the background of school-enterprise cooperation, Die \& Mould Indurstry, 2014, vol. 40(2), pp. 67-69.

[6] Bi Dasen, Li Yuntao and Zhu liang. Teaching reform of top-level personnel training for die \& mould major of undergraduate colleges, Die \& Mould Indurstry, 2012, vol. 38(2), pp. 69-75.

[7] Linda P. Blanton, Marleen C. Pugach. Using a classification system to probe the meaning of dual licensure in general and special education, Teacher, Education and Special Education, 2011, vol. 34(3), pp. 219-234. https://doi.org/10.1177/0888406411404569

[8] Stefan Hummelsheim, Michaela Baur, The German dual system of initial vocational education and training and its potential for transfer to Asia, Prospects, 2014, vol. 44(2), pp. 276-296. https://doi.org/10.1007/s11125-014-9311-4 
Paper-Exploration and Practice on Course Teaching in Plastic Injection Mold

[9] Zhang Shize, liu Tongxian, Ding Shenxuan and Lv Shumin. Research on the development, application and suggestion of project teaching method, Education and Teaching Forum, 2014 vol. (50), pp. 168-169.

[10] Gulimzhan Zhylkybay, Saule Magzhan, Zhanar Suinzhanova, Myrzakhmet Balaubekov and Pakizat Adiyeva. The effectiveness of using the project method in the teaching process, Procedia - Social and Behavioral Sciences, 2014, vol. 143, pp. 621-624. https://doi.org/10.1016/j.sbspro.2014.07.448

[11] Emine Şenyuva Hülya Kaya and Gönül Bodur. Effect social skills of nursing students of the project based teaching method, Procedia - Social and Behavioral Sciences, 2014, vol. 152, pp. 393-398. https://doi.org/10.1016/j.sbspro.2014.09.218

\section{Author}

Xin Li is a lecturer in the College of Electrical and Mechanical Engineering, Agricultural University of Hebei, Baoding 071001, China (lixin20131113@163.com).

Article submitted 25 February 2018. Resubmitted 03 March 2018. Final acceptance 25 April 2018. Final version published as submitted by the author. 